\title{
Diffusive sampling of air pollutants in US basins with oil and gas development
}

\author{
R. A. Field ${ }^{1}$, A. Ramirez ${ }^{1}$, J. Quintanilla ${ }^{1}$, A. Cabrerizo ${ }^{2}$ \\ \& P. Pérez Ballesta ${ }^{2}$ \\ ${ }^{1}$ Department of Atmospheric Science, University of Wyoming, USA \\ ${ }^{2}$ European Commission, Joint Research Centre, \\ Institute for Environment and Sustainability, Air and Climate Unit, Italy
}

\begin{abstract}
Emissions from the oil and gas sector are important for climate change, ozone production and human health. Oil and gas leakage rates reported in the United States (US), estimated by relating measured methane fluxes with natural gas production, vary from less than 1\% (e.g. Upper Green River Basin, (UGRB) in Wyoming) to over 6\% (Uintah Basin, Utah). We demonstrate the applicability of the Pocket Diffusive (POD) sampler for scoping assessments of levels hydrocarbons and volatile polycyclic aromatic hydrocarbons (PAH) in areas heavily influenced by existing O\&G development. We assess three US basins (Upper Green River, Uintah, and North Platte River), each with different characteristics, most importantly meteorology and emissions, which influence measured air quality. We contrast ambient concentrations of hydrocarbons $\left(\mathrm{C}_{4^{-}}\right.$ $\mathrm{C}_{12}$ ) and volatile PAHs at these basins and show important differences between measured levels of pollutants, including benzene. Our POD sampling results support previous findings of relatively elevated levels of aromatics in the Pinedale Anticline (UGRB) and relatively high alkane concentrations in the Uintah Basin. Concentrations of alkenes and PAH shows that these compound classes are at relatively low levels, and as such are of less concern in the assessed basins.

Keywords: oil and gas, hydrocarbons, diffusive sampling.
\end{abstract}




\section{Introduction}

Driven by the development of hydraulic fracturing ("fracking") the oil and natural gas $(O \& G)$ sector in the United States (US) has undergone rapid expansion in recent years. While the impact of the global downturn of the price of oil is reducing exploration activities production in many US states remains at historically high levels [1]. Increased unconventional O\&G development from coal, sandstone, and shale deposits in the US has also created air quality impacts. A variety of measurement-based approaches including mobile monitoring, fixed site network stations, airborne, and satellite platforms have been applied to improve our understanding of the behaviour of O\&G emission sources.

Emissions from $\mathrm{O} \& \mathrm{G}$ sources are classified by air regulatory agencies as point sources (emitted from a stack or pipe), mobile sources (from trucks, trains, drill rigs), and fugitive sources (e.g. emissions due to equipment leaks). Fugitive emissions are difficult to quantify because they can be difficult to detect and may be intermittent. Quantifying emissions from the O\&G production is complicated by the wide variety of emission sources that can be spread over tens of thousands of acres of a development area, and this increases uncertainty associated with assessment of local and regional air quality impacts. Emissions from unconventional O\&G production are from drilling, completion, production and transmission activities [2]. Close to producing well pads, emissions are concentrated and combustion (engines), processing (separators) and fugitive (leakage) sources are most important.

Hydrocarbon emissions are of prime importance as methane $\left(\mathrm{CH}_{4}\right)$ is an important greenhouse gas and non-methane hydrocarbons (NMHC) are ozone $\left(\mathrm{O}_{3}\right)$ precursors, some of which are hazardous air pollutants. Determining the air pollutants that will be of most concern begins with understanding activities and processes that are present. The chemical composition of the extracted product is of particular importance. Wet natural gas, dry natural gas, and oil wells have different product handling approaches and therefore different associated air emission sources. Wet gas contains complex hydrocarbons from natural gas liquids (ethane, propane, butanes) and condensate, which is a mix of longer chain $\left(\mathrm{C}_{5}{ }^{+}\right)$and cyclic hydrocarbons (cycloalkanes and aromatics), whereas dry natural gas is predominately $\mathrm{CH}_{4}$. Because wet gas usually contains a more complex mixture of hydrocarbons than dry gas, the variety of VOC and other air emissions from wet gas is greater. Aromatic hydrocarbons, including benzene, toluene, ethylbenzene and xylenes (BTEX) are of particular importance when considering the handling of wet gas. Furthermore, wells producing crude oil, a complex mixture of hydrocarbons that generally have from five to 40 carbon atoms per molecule, have different air emissions. In broad terms, hydrocarbons with lower volatility (a greater number of carbon atoms) are less likely to be emitted to the atmosphere during production.

As drilling, production and transmission activities in the US have encroached on residential and urban areas, attention has turned to the impact of O\&G emissions on ambient air quality and human health [3]. The US Government Accountability Office [3] has reported that cumulative air quality impacts are 
difficult to determine as the extent and severity of risks vary significantly within and between developments due to location and process driven factors. As such, one size does not fit all, and the importance of location specific assessment has emerged.

Research in the US has shown that total emissions from a variety of basins in the US can have different $\mathrm{CH}_{4}$ fluxes that indicate a wide range of leakage rates based upon production. Leakage rates from the Upper Green River Basin (UGRB) of less than $1 \%$ [4] contrast with those of $6+\%$ for the Uintah Basin [5]. The results presented here are from surveys at three different basins in the US dominated by emissions from O\&G activities. These surveys were performed in conjunction with the SONGNEX (Studying the Atmospheric Effects of Changing Energy Use in the US at the Nexus of Air Quality and Climate Change) project led by NOAA [6]. Figure 1 shows SONGNEX flight path and indicates the location of the UGRB and Uintah Basin. The North Platte River Basin is located directly to the south of the Powder River Basin and to the north of the Denver Julesburg Basin.

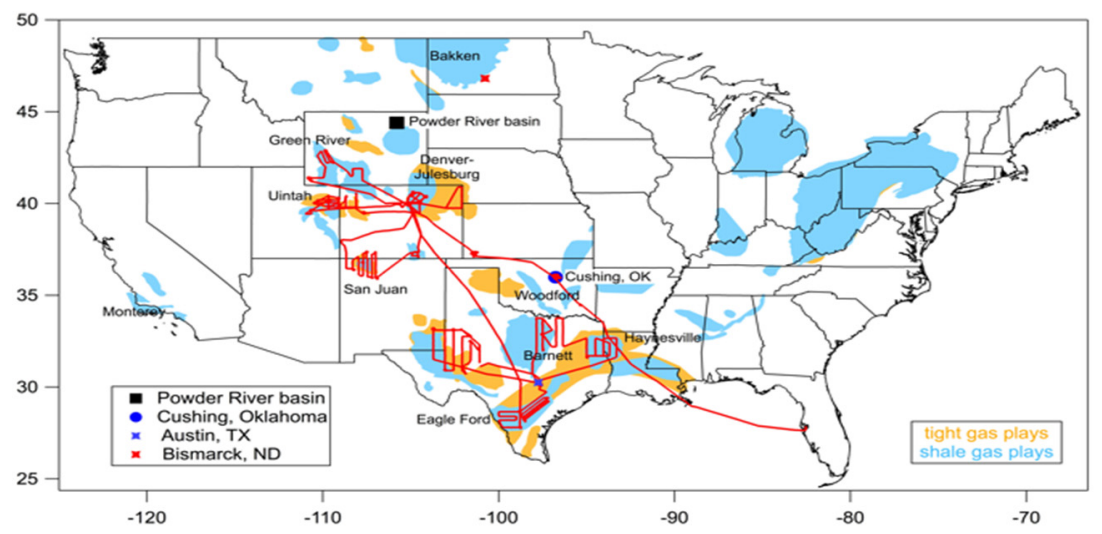

Figure 1: SONGNEX flights and selected basins with O\&G development.

\section{Methodology}

\subsection{Basins}

Surveys were performed in three basins with contrasting situations in terms of geography, meteorology and anticipated O\&G emissions. The UGRB is located in Sublette County Wyoming, a remote area of the US, with significant O\&G development. The UGRB is the home to three important O\&G developments: the Big Piney/La Barge area; the Jonah Field; and the Pinedale Anticline. The latter two are unconventional developments ranked in the top 10 of US onshore gas fields. The Jonah Field and Pinedale Anticline are also ranked in the top 100 of onshore oil fields in the US [7]. By contrast the La Barge/Big Piney area is predominately a conventional oil development. Of the 6600 wells in the UGRB 
$\sim 2700$ are in the Pinedale Anticline, 2000 are in Jonah, and $\sim 700$ are in La Barge/Big Piney area. The phenomenon of wintertime $\mathrm{O}_{3}$ was first reported in the UGRB as a result of emissions from the Pinedale Anticline and Jonah Field [8]. Pollutant emissions in the UGRB are almost entirely from O\&G activities [9] with minimal contributions from other sources. Modelling studies of 2011 wintertime $\mathrm{O}_{3}$ in the $\operatorname{UGRB}[10,11]$ have demonstrated that $\mathrm{O}_{3}$ production is critically dependent upon NMHC.

The Uintah Basin in northeastern Utah, in common with the UGRB in Wyoming, is associated with wintertime $\mathrm{O}_{3}$ that is driven by $\mathrm{O} \& \mathrm{G}$ emissions. Significant scientific progress for understanding wintertime $\mathrm{O}_{3}$ production was made through three winter campaigns led by NOAA [12, 13]. This work highlighted the importance of using measurement-based input for predictive modelling and revealed the importance of secondary carbonyl compounds as radical amplifiers. The Uintah Basin region is still being developed but has $\sim 8000$ gas wells and $\sim 2000$ oil wells in operation.

The Converse County portion of the North Platte Basin is an area with a long history of $\mathrm{O} \& \mathrm{G}$ development that continues to the present day with an environmental impact statement under consideration by the US Bureau of Land Management for an additional 5,000 wells. Historically this region of the US has experienced considerable oil exploration. There are $\sim 1100$ O\&G active wells in Converse County with an additional 1300 inactive wells. Over 95\% of wells in Converse County are classified as oil wells. Recent development in the extensive Niobrara formation accounts for $\sim 170$ new wells. This basin provides an opportunity to assess conditions with relatively low production levels at the present time.

\subsection{Sampling device}

Diffusive sampling has been successfully applied to monitor contaminants in air for many decades [14]. Diffusive sampling is an effective tool for environmental and personal exposure monitoring, as there are few limitations for deployment location. Applications have included a wide range of environmental conditions including indoor, workplace and ambient air environments, with pollutant concentrations ranging from trace to highly contaminated levels [15-17]. While advances of continuous analyzers have led to mobile monitoring for understanding some air quality problems, diffusive sampler surveying remains an effective approach for detailed understanding of spatial distributions with simultaneous measurements. Diffusive sampling surveys are well suited to define the extent of pollution problems.

This study employs a new prototype diffusive sampler known as the Pocket Diffusive (POD) sampler that is designed to ensure a constant diffusion rate during the defined sampling period. The POD sampler is suitable for application in a wide range of environmental conditions. A patent (13792334.8-1553 EPO) has been awarded for the POD sampler [18]. In this study two types of POD sampler were used: (i) a POD sampler with stainless steel diffusion body of $20 \mu \mathrm{m}$ porosity for the analysis of VOCs; and (ii) a POD sampler with a bronze 
diffusion body of $60 \mu \mathrm{m}$ porosity for the analysis of volatile polycyclic aromatic hydrocarbons (PAHs). Figure 2 shows details of the POD sampler.

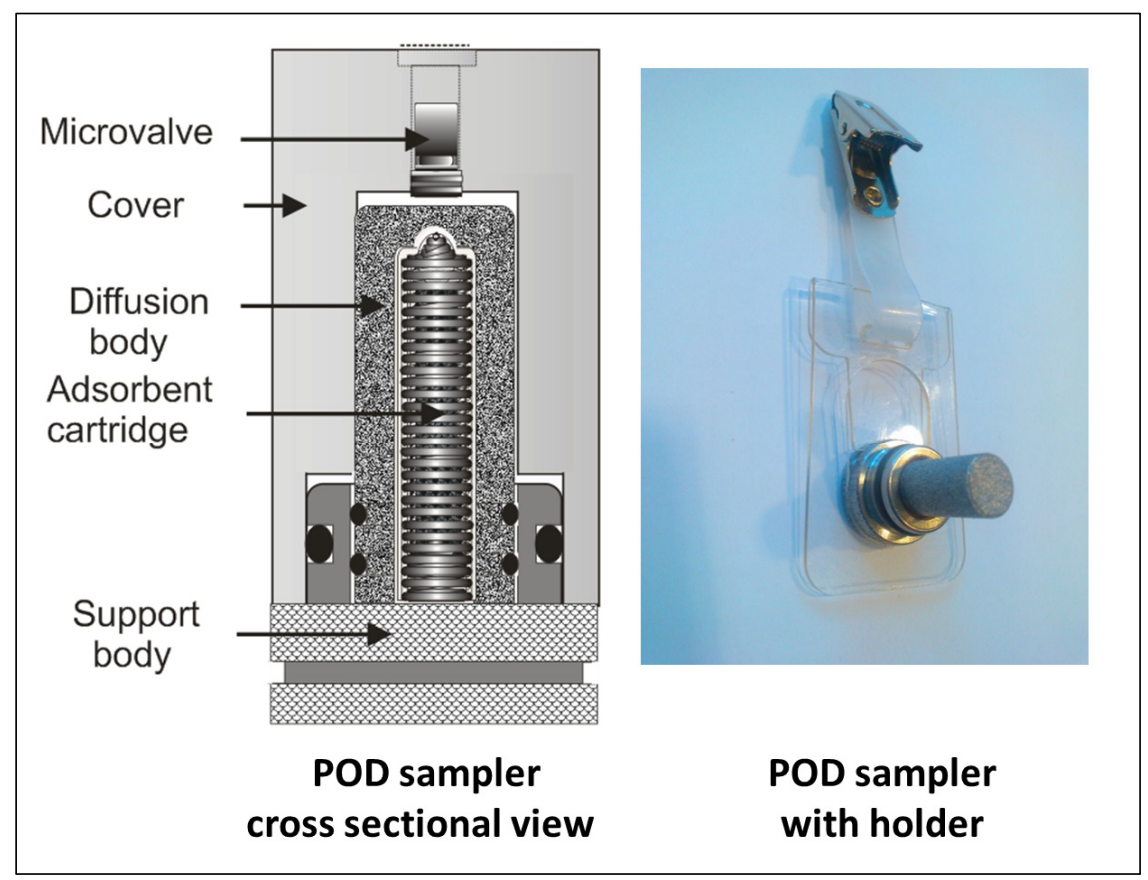

Figure 2: Pocket Diffusive (POD) sampler design.

\subsection{Analytical method}

Analysis of VOCs was carried out by thermal desorption using a Perkin Elmer Turbomatrix thermal desorption system (AT50) coupled with an Agilent gas chromatograph CG 6890 with a double column (DB1-DB624) and a Mass Spectrometer 5890 . Cylinders of certified reference material supplied by the UK National Physical Laboratory for 33 hydrocarbons at $4 \mathrm{ppb}$ were used for calibration of the gas chromatograph. Known amounts of these standard mixtures were loaded onto Perkin Elmer glass tubes containing from $35 \mathrm{mg}$ to $300 \mathrm{mg}$ of Carbopack-X 60-80 mesh. Loaded volumes from $100 \mathrm{ml}$ to 20 liters, depending on the concentration of the standard, allow calibration of the system from 0 to $2 \mu \mathrm{g}$ for individual compounds. Breakthrough volumes were checked with a backup tube in series during loading of the standard mixture.

Analysis of PAHs was also carried out by thermal desorption using a TDU injector from Gerstel coupled with a Agilent gas chromatograph GC6890 and a Mass Spectrometer MS 6975C inter MSD from Agilent Technologies with a capillary column RXI-17Sil MS 50m, $0.250 \mathrm{~mm}$ i.d. and $0.150 \mu \mathrm{m}$. The system was calibrated by means of certified reference solutions containing the target and 
corresponding deuterated compound. An internal standard technique was applied for the quantification of target compounds in the samples.

\subsection{Site selection}

Circa 100 POD samplers of each type (VOCs and PAHs) were co-located in each of the three studied basins. Site selection for each basin was based upon existing knowledge of the air quality in the regions. For the UGRB extensive measurements have been performed since 2005. For the Uintah Basin intensive measurements started in 2009 upon realization that wintertime $\mathrm{O}_{3}$ was important in Utah, not only Wyoming. For the North Platte River Basin (Converse County) measurements only started in 2012 as part of State and Federal efforts to better understand baseline conditions in advance of significant $O \& G$ development in the area. Sites were selected with reference to understanding gained in numerous assessments funded by State and Federal agencies. These three basins were selected due to the similarities and differences that they presented in terms production of oil, gas and water (see table 1). Production data was accessed from Wyoming Oil and Gas Conservation Commission [19] and Utah Oil and Gas [20].

Table 1: Average monthly oil and gas production in the studied areas during 2014.

\begin{tabular}{|cccccc}
\hline Basin & $\begin{array}{c}\text { Oil } \\
\text { (barrels) }\end{array}$ & Gas (Mcf) & $\begin{array}{c}\text { Water } \\
\text { (barrels) }\end{array}$ & Gas/water & Water/oil \\
\hline $\begin{array}{c}\text { Converse } \\
\text { County }\end{array}$ & $1,068,339$ & $3,049,573$ & 983,906 & 3.1 & 0.9 \\
\hline $\begin{array}{c}\text { La } \\
\text { Barge/Big } \\
\text { Piney }\end{array}$ & 17,076 & 823,350 & 87,543 & 9.4 & 5.1 \\
\hline $\begin{array}{c}\text { Pinedale } \\
\text { Anticline }\end{array}$ & 300,038 & $40,122,047$ & $1,403,306$ & 28.6 & 4.7 \\
\hline $\begin{array}{c}\text { Jonah } \\
\text { Field }\end{array}$ & 152,817 & $15,726,339$ & 330,876 & 47.5 & 2.2 \\
\hline $\begin{array}{c}\text { Uintah } \\
\text { Basin }\end{array}$ & $2,744,675$ & $30,252,764$ & $9,253,200$ & 3.3 & 3.4 \\
\hline
\end{tabular}

The La Barge/Big Piney area in the UGRB is predominately conventional oil wells in an aging field that has potential for infill development. The Pinedale Anticline is an active field with considerable production of gas, condensate and water in the past 10 years. The Jonah Field was developed earlier than the Pinedale Anticline and while production is similar, albeit with relatively less water production, the field differs by having less directional drilling, with more well pads and on pad liquids storage in tanks. The Uintah Basin is characterised by older oil development in the East and more recent wet gas production in the West, the latter was the focus for this study. The Converse County region of the 
North Platte River Basin is an oil rich area that has many old and inactive well with high levels of development anticipated. While sampling site density in relation to well density varied between the different basins a representative coverage was achieved in each basin.

\section{Results and discussion}

Although the sampling time was similar for all samplers (three days), the meteorological conditions differed considerably despite the three surveys being performed in less than a 5-week period. Table 2 shows the average meteorological conditions for corresponding sampling periods at each basin. Converse County had higher wind velocities with the subsequent dilution effect on emissions. The highest temperatures were observed during the sampling period in Uintah Basin, whilst the lower temperatures characterized the sampling in the UGRB.

Table 2: Meteorological conditions for sampling at each basin.

\begin{tabular}{|lcccccc|} 
Basin & $\begin{array}{c}\text { Start } \\
\text { date }\end{array}$ & $\begin{array}{c}\text { End } \\
\text { date }\end{array}$ & $\begin{array}{c}\text { Temp. } \\
{ }^{\circ} \mathbf{C}\end{array}$ & $\begin{array}{c}\text { RH } \\
\text { \% }\end{array}$ & $\begin{array}{c}\text { Wind } \\
\mathbf{m} / \mathbf{s}\end{array}$ & $\begin{array}{c}\text { Pressure } \\
\text { mbars }\end{array}$ \\
\hline $\begin{array}{l}\text { Converse } \\
\text { County }\end{array}$ & $31 / 3 / 2015$ & $3 / 4 / 2015$ & 6.1 & 39 & 6.0 & 822 \\
\hline $\begin{array}{l}\text { Uintah } \\
\text { Basin }\end{array}$ & $21 / 4 / 2015$ & $24 / 4 / 2015$ & 12.5 & 42 & 2.4 & 845 \\
\hline UGRB & $7 / 4 / 2015$ & $10 / 4 / 2015$ & 0.1 & 76 & 3.2 & 777 \\
\hline
\end{tabular}

Concentrations of selected alkanes, alkenes, aromatics and polycyclic aromatic hydrocarbons determined in the studied basins are reported in Figures 3, 4, 5 and 6, respectively. The specific compounds measured in each of the aforementioned hydrocarbon classes are given in the relevant figure. The error bars in these figures represent the standard deviation of the sample's mean value. These concentrations represent the average concentration over the integrated period of measurement of the samplers (in this particular case, three days). Despite lower gas production (see table 1.) $\mathrm{C}_{5}$ alkanes that are strongly associated with gas production are higher in the Uintah basin compared to the Pinedale Anticline. This finding appears to support the hypothesis generated from basin wide flux measurements of $\mathrm{CH}_{4}$ that indicate higher leakage rates in the Uintah Basin compared to the Pinedale Anticline [4].

Compared to alkanes, alkenes are measured at very low levels. This is in contrast to areas influenced by urban emissions and, in particular, traffic emissions [21]. 


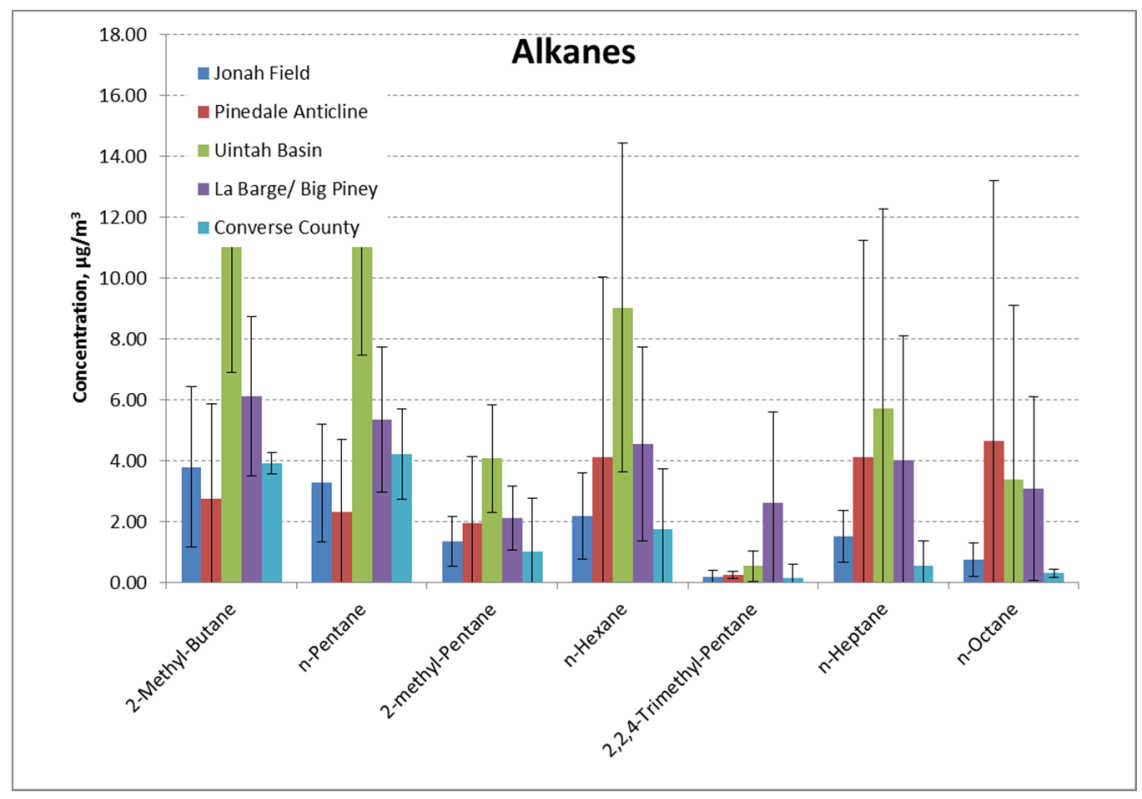

Figure 3: Mean concentration of alkanes in the studied basins.

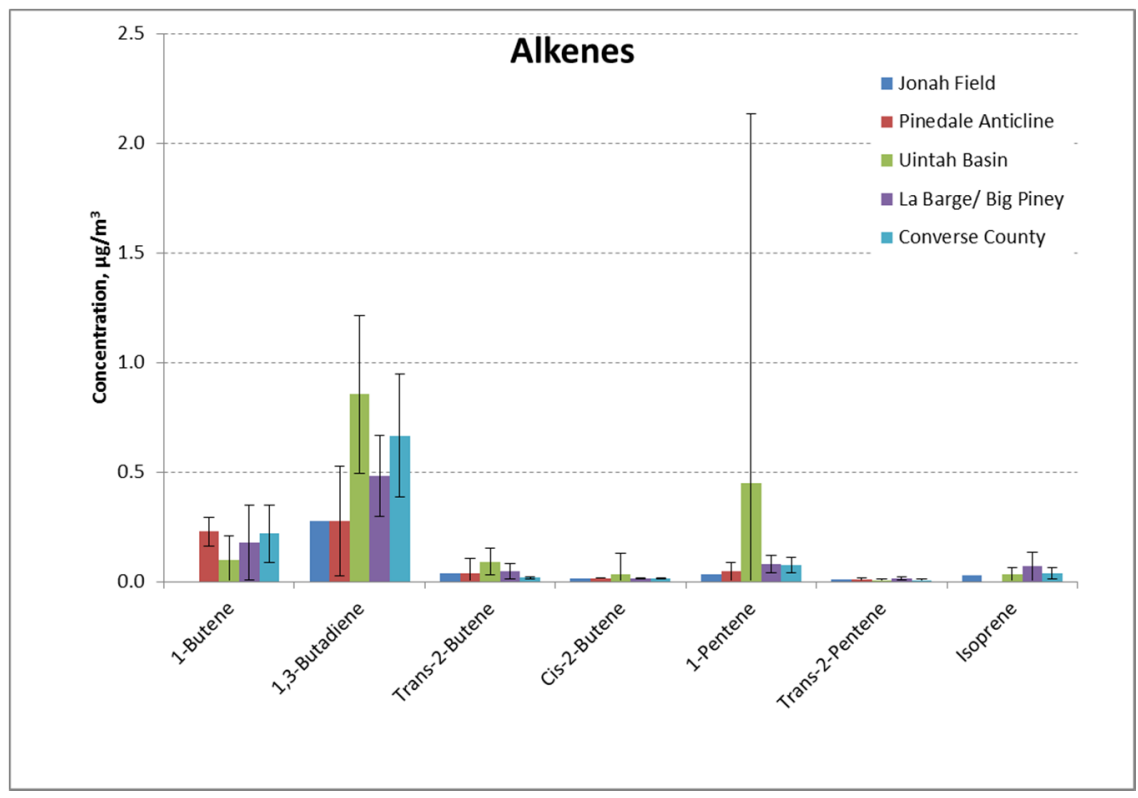

Figure 4: Mean concentration of alkenes in the studied basins. 
Natural gas composition is dominated by alkanes without measurable contributions from alkenes. As such measured alkenes are from combustion emission sources. In the $O \& G$ dominated basins in this study alkenes are produced from drilling, compression and vehicle exhaust emission sources.

While some of the sampling locations selected for the Pinedale Anticline were within areas previously reported as BTEX hotspots [22], the elevation of ambient concentrations of benzene, toluene and $\mathrm{m}+\mathrm{p}$-xylene compared to the Jonah Field and Uintah Basin illustrated by fig. 5 is striking. Field et al. [23] reported extremely high concentrations of BTEX downwind of a water treatment and recycling facility, and noted the significance for wintertime ozone formation. High BTEX was also reported by Field et al. [22] at an area of the Pinedale Anticline known as the Mesa. This area has a high density of development activities with significant emissions of BTEX from exploration and production activities, most importantly dehydration of extracted hydrocarbon product. BTEX emissions are significant due their dual role as air toxics, or hazardous air pollutants, and as $\mathrm{O}_{3}$ precursors. The concentrations of BTEX given in fig. 5 indicate the potential importance of O\&G sources to urban levels, if development activities are close to, or within, cities. Despite insignificant contributions from traffic, the main source for population exposure to BTEX, the levels in fig. 5 are comparable to those reported in Los Angeles, California [21]. Benzene concentrations at some hotspot locations were higher than the annual limit value for ambient air quality established by the European Directive 2008/50/EC.

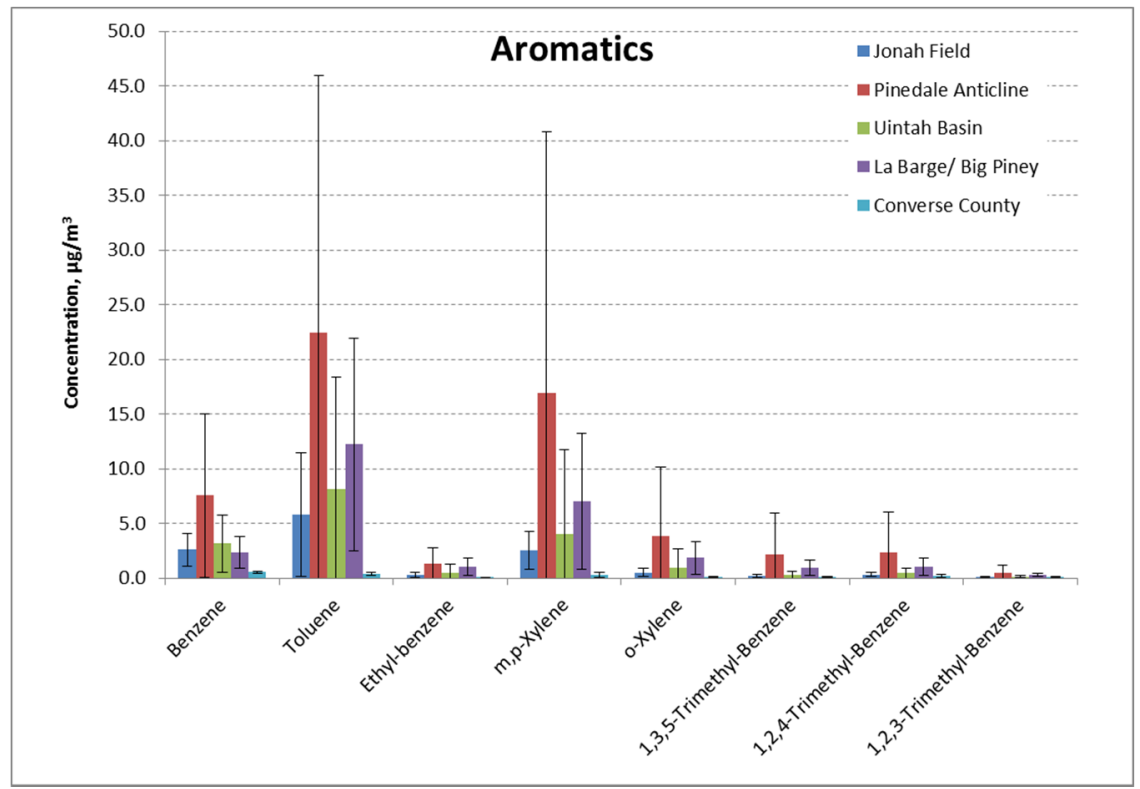

Figure 5: Mean concentration of aromatics in the studied basins. 
The concentrations determined for selected PAHs in the different basins are reported in fig. 6 . By contrast with VOC, PAH levels are relatively consistent at very low background levels.

The concentration of pollutants differs drastically among basins. The highest concentrations of alkanes, and to a lesser extent alkenes, were measured in the Uintah Basin. By contrast the Pinedale Anticline shows the highest concentrations for aromatics and PAHs. Within a particular basin, important factors likely include the number of proximate well pads in the surroundings, and the type and level of activities resulting in pollutant emissions. The interplay of a number of emission and dispersion related factors are expected to characterize the measured concentrations at each sampling location.

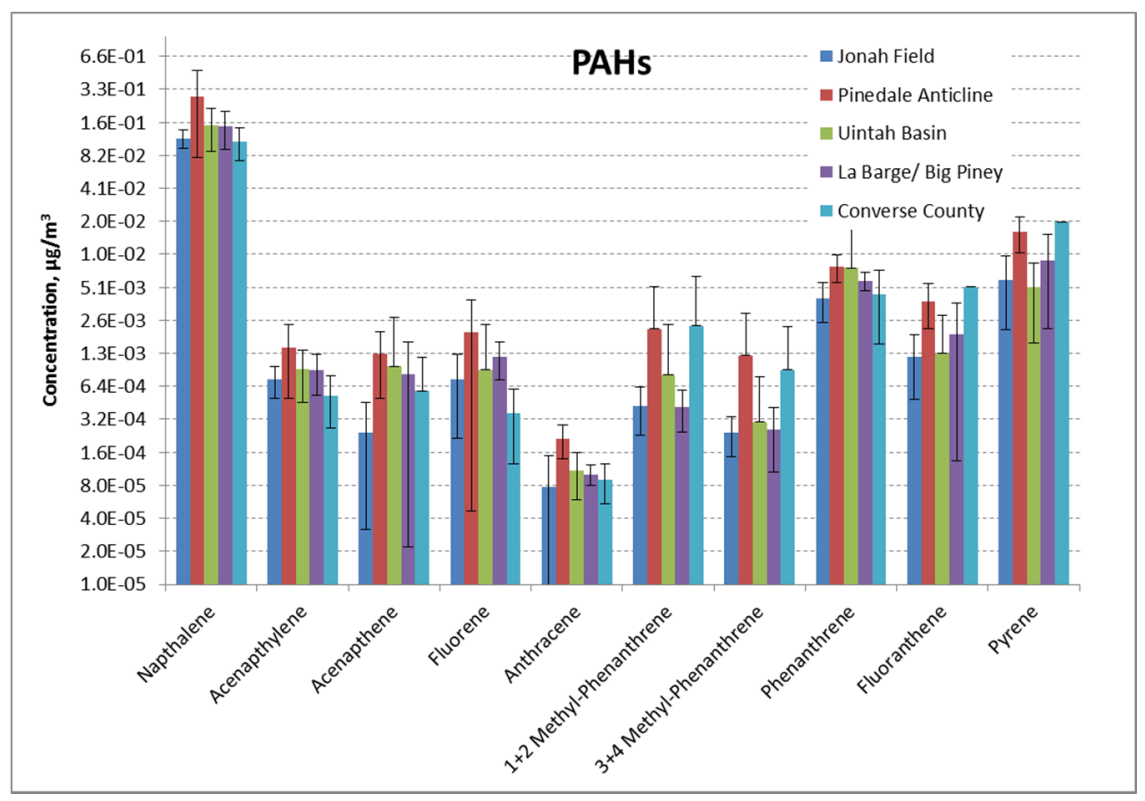

Figure 6: Mean concentration of PAHs in the studied basins.

\section{Conclusions}

POD samplers are effective for measuring air pollutant distributions over wide spatial areas. Hydrocarbon measurements with POD samplers can show the importance of $\mathrm{O} \& \mathrm{G}$ emission sources to air quality. During this assessment, benzene concentrations at some hotspot locations were higher than the annual limit value for ambient air quality established by the European Directive 2008/50/EC. The North Platte Basin has a relatively low impact from O\&G development. This region has strong ventilation due to the influence of the Wyoming wind corridor. The UGRB has a clear impact from O\&G development. The ambient values of hydrocarbons within the Pinedale Anticline and Jonah Field are anticipated given the high natural gas production volumes. 
Measurements at the UGRB support previously reported relatively high BTEX levels in the Pinedale Anticline. The Uintah Basin also has a relatively high impact from O\&G development. Despite lower production values compared to the UGRB ambient $\mathrm{C}_{5}$ alkane levels are relatively high reinforcing the current hypothesis that this basin has a high leakage rate compared to other natural gas fields in the region and the rest of the US.

\section{References}

[1] US Energy Information Administration, Annual Energy Outlook 2015 Report, Washington DC, 2015a.

[2] Field, R.A., Soltis, J. \& Murphy, S., Air quality concerns of unconventional oil and natural gas production. Environmental Science. Processes \& Impacts, 16(5), pp. 954-69, 2014, doi:10.1039/c4em00081a

[3] US Government Accountability Office, GAO-12-732 Report to congressional requesters, oil and gas: Information on shale resources, development, and environmental and public health risks, Washington DC, 2012.

[4] Murphy, S., Field, R.A., Soltis, J., Edie, R., and Snare, D., Reconciling airborne basin scale methane flux estimates with ground based quantification of methane and VOC emissions from well pads. $A G U$ Conference Presentation A11L-03 at Atmospheric Impacts of Oil and Gas Development I, San Francisco CA, 2014.

[5] Karion, A., Sweeney, C., Pétron, G., Frost, G., Hardesty, R.M., et al., Methane emissions estimate from airborne measurements over a western United States natural gas field. Geophysical Research Letters, 40(16), pp. 4393-4397, doi:10.1002/grl.50811

[6] US National Oceanic and Atmospheric Administration (NOAA), SONGNEX 2015 White Paper, http://www.esrl.noaa.gov/csd/ projects/songnex/

[7] US Energy Information Administration, Top 100 U.S. oil and gas fields, 2015b, http:/www.eia.gov/naturalgas/crudeoilreserves/top100/pdf/ top100.pdf

[8] Schnell, R.C., Oltmans, S.J., Neely, R.R., Endres, M.S., Molenar, J.V., et al., Rapid photochemical production of ozone at high concentrations in a rural site during winter. Nature Geoscience, 2, pp. 120-122, doi:10.1038/ngeo415

[9] WDEQ (Wyoming Department of Environmental Quality), Actual Emission Inventories, 2014, http://deq.wyoming.gov/aqd/emissioninventories/resources/actual-emissions-inventory/

[10] Carter, W.P.L., and Seinfeld, J.H., Winter ozone formation and VOC incremental reactivities in the Upper Green River basin of Wyoming. Atmospheric Environment, 50, pp. 255-66, 2012, doi:10.1016/ j.atmosenv.2011.12.025

[11] Rappenglück, B., Ackermann, L., Alvarez, S., Golovko, J., Buhr, M., et al., Strong wintertime ozone events in the Upper Green River basin, 
Wyoming. Atmospheric Chemistry and Physics 14(10), pp. 4909-34, 2014, doi:10.5194/acp-14-4909-2014

[12] Edwards, P.M., Brown, S.S., Roberts, J.M., Ahmadov, R., Banta, R.M., et al., Unconventional photochemistry underlying winter ozone in an oil and gas producing region. Nature, 514, pp. 351-354, 2014, doi:10.1038/ nature13767, 2014

[13] Ahmadov, R., McKeen, S., Trainer, M., Banta, R., Brewer, A., et al., Understanding high wintertime ozone pollution events in an oil and natural gas producing region of the western US. Atmospheric Chemistry and Physics, 15, pp. 411-429, 2015, doi: 10.5194/acp-15-411-2015

[14] Kot-Wasik, A., Zabiegała, B., Urbanowicz, M., Dominiak, E., Wasik, A., et al., Advances in passive sampling in environmental studies. Analytica Chimica Acta, 602(2), pp.141-63, 2007, doi:10.1016/j.aca.2007.09.013

[15] Walgraeve, C., Demeestere, K., Dewulf, J., Van Huffel, K., and Van Langenhove, H., Diffusive Sampling of 25 Volatile organic compounds in indoor air: Uptake rate determination and application in Flemish homes for the elderly. Atmospheric Environment, 45(32) pp. 5828-36, 2011, doi:10.1016/j.atmosenv.2011.07.007

[16] Pérez Ballesta, P., Field, R.A., Connolly, R., Cao, N., Baeza Caracena, A., et al., Population exposure to benzene: One day cross-sections in six European cities. Atmospheric Environment, 40(18), pp. 3355-366, 2006, doi:10.1016/j.atmosenv.2006.01.053

[17] Carrieri, M., Bartolucci, G.B., Paci, E., Sacco, P., Pigini, D., et al., Validation of a radial diffusive sampler for measuring occupational exposure to 1,3-butadiene. Journal of Chromatography, A 1353, pp.114120, 2014, doi:10.1016/j.chroma.2014.02.018

[18] Pérez Ballesta, P., Diffusive sampling device, Patent WO 2014/076153A1. $0522,2014$.

[19] Wyoming Oil \& Gas Conservation Commission, Data base for Production by Field, Pinedale and Jonah records, 2015, http://wogcc.state.wy.us/

[20] Utah Oil \& Gas, Data base by Field and County, 2015, http://oilgas.ogm.utah.gov/Statistics/Statistics.cfm

[21] Warneke, C., de Gouw, J.A., Holloway, J.S., Peisch, J., Ryerson, T.B., et al., Multiyear trends in volatile organic compounds in Los Angeles, California: Five decades of decreasing emissions. Journal of Geophysical Research, 117, D00V17, 2012, http://dx.doi.org/10.1029/2012JD017899

[22] Field, R.A., Soltis J., Pérez-Ballesta, P., Grandesso, E., \& Montague D.C., Distributions of air pollutants associated with oil and natural gas development measured in the Upper Green River basin of Wyoming. Elementa Sci. Anthropocene, 3, 000074, 2015a, doi:10.12952/ journal.elementa.000074

[23] Field, R.A., Soltis, J, McCarthy, M.C., Murphy, S., \& Montague, D.C., Influence of oil and gas field operations on spatial and temporal distributions of atmospheric non-methane hydrocarbons and their effect on ozone formation in winter. Atmospheric Chemistry and Physics, 15(6), pp. 3527-42, 2015b, doi:10.5194/acp-15-3527-2015 